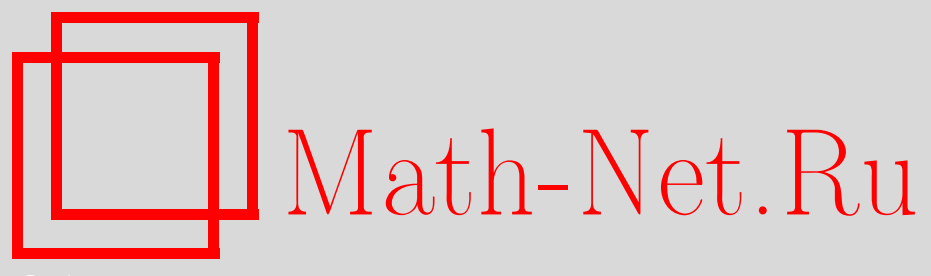

Д. А. Митькин, Об оценке некоторых арифметических сумм с числом делителей, Матем. заметки, 2006, том 80, выпуск 3, 471-472

DOI: https://doi.org/10.4213/mzm2835

Использование Общероссийского математического портала Math-Net.Ru подразумевает, что вы прочитали и согласны с пользовательским соглашением http://www . mathnet.ru/rus/agreement

Параметры загрузки:

IP: 35.174 .16 .151

26 апреля 2023 г., 14:04:49

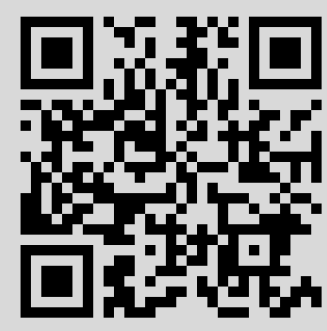




\section{ОБ ОЦЕНКЕ НЕКОТОРЫХ АРИФМЕТИЧЕСКИХ СУММ С ЧИСЛОМ ДЕЛИТЕЛЕЙ}

\section{Д. А. Митькин}

Пусть $\tau_{k}(n)$ при натуральных $k, n$ обозначает число решений уравнения $x_{1} \cdots x_{k}=n$ в натуральных числах $x_{1}, \ldots, x_{k}$. В частности, считаем, что

$$
\tau_{1}(n)=1 \quad, \quad \tau_{2}(n)=\tau(n) .
$$

Целью статьи является уточнение оценки К. К. Марджанишвили [1]

$$
\sum_{n \leqslant X}\left(\tau_{k}(n)\right)^{l} \leqslant A_{k}^{(l)} X\left(\ln X+k^{l}-1\right)^{k^{l}-1},
$$

где

$$
A_{k}^{(l)}=k^{l}(k !)^{-\left(k^{l}-1\right) /(k-1)} \quad \text { при } \quad X \geqslant 1 .
$$

Рассматривая суммы с наименьшим общим кратным вида

$$
S_{X}(k, l)=\sum_{\left[d_{1}, \ldots, d_{k}\right] \leqslant X} \frac{\left(\tau\left(\left[d_{1}, \ldots, d_{k}\right]\right)\right)^{l}}{\left[d_{1}, \ldots, d_{k}\right]},
$$

автор [2] установил оценку

$$
\sum_{n \leqslant X}(\tau(n))^{k} \leqslant \frac{X}{\left(2^{k}-1\right) !}\left(\ln X+\frac{11}{9}\left(2^{k}-1\right)\right)^{2^{k}-1} .
$$

В настоящей статье доказывается неравенство $\tau_{k}(n) \tau_{l}(n) \leqslant \tau_{k l}(n)$, которое в сочетании с известной оценкой

$$
\sum_{n \leqslant X} \tau_{k}(n) \leqslant \frac{X}{(k-1) !}(\ln X+k-1)^{k-1}
$$

позволяет получить следующее уточнение оценки (1):

$$
\sum_{n \leqslant X}\left(\tau_{k}(n)\right)^{l} \leqslant \frac{X}{\left(k^{l}-1\right) !}\left(\ln X+k^{l}-1\right)^{k^{l}-1} .
$$

Лемма 1. Для любых натуральных $k \geqslant 2, l \geqslant 2$ и п справедливо неравенство

$$
\tau_{k}(n) \tau_{l}(n) \leqslant \tau_{k l}(n) .
$$

ДокАзАТЕльство. Так как $\tau_{k}(n) \tau_{l}(n)$ и $\tau_{k l}(n)$ - положительные мультипликативные функции, неравенство (2) достаточно доказать при $n$, равном степени простого числа. При простом $p$ и натуральных $m \geqslant 2, \alpha$ справедлива формула (см. [3; гл. 2, вопрос 11b])

$$
\tau_{m}\left(p^{\alpha}\right)=\frac{(\alpha+1)(\alpha+2) \cdots(\alpha+m-1)}{1 \cdot 2 \cdots(m-1)}=\frac{m(m+1) \cdots(m+\alpha-1)}{1 \cdot 2 \cdots \alpha},
$$

поэтому неравенство $\tau_{k}\left(p^{\alpha}\right) \tau_{l}\left(p^{\alpha}\right) \leqslant \tau_{k l}\left(p^{\alpha}\right)$ эквивалентно неравенству

$$
\prod_{j=0}^{\alpha-1} \frac{(k+j)(l+j)}{(1+j)^{2}} \leqslant \prod_{j=0}^{\alpha-1} \frac{k l+j}{1+j},
$$

которое справедливо как следствие очевидного неравенства $(k+j)(l+j) \leqslant(k l+j)(1+j)$ при $j=0,1, \ldots, \alpha-1$. Лемма доказана.

(C) Д. А. Митькин, 2006 
ЗАмечАниЕ. Аналогично доказывается и более общее неравенство

$$
\tau_{k}(n) \tau_{l}(n) \leqslant \tau_{m}(n) \tau_{s}(n),
$$

где натуральные числа $k, l, m, s$ подчинены условиям $k l=m s, k+l<m+s$.

Индукцией по $l \geqslant 2$ из леммы 1 получается следующее следствие.

СледСтвиЕ. При любъх натуралъных $n$ u $l \geqslant 2, k_{1} \geqslant 2, \ldots, k_{l} \geqslant 2$ справедливо неравенство

$$
\tau_{k_{1}}(n) \cdots \tau_{k_{l}}(n) \leqslant \tau_{k_{1} \cdots k_{l}}(n) .
$$

ЛЕмма 2 [4; с. 358]. При любом натуральном $k \geqslant 2$ и при любом $X \geqslant 1$ справедлива оченка

$$
\sum_{n \leqslant X} \tau_{k}(n) \leqslant \frac{X}{(k-1) !}(\ln X+k-1)^{k-1} .
$$

Теорема. При любых натуральных $l, k_{1} \geqslant 2, \ldots, k_{l} \geqslant 2$ и любом $X \geqslant 1$ справедлива оценка

$$
\sum_{n \leqslant X} \tau_{k_{1}}(n) \cdots \tau_{k_{l}}(n) \leqslant \frac{X}{\left(k_{1} \cdots k_{l}-1\right) !}\left(\ln X+k_{1} \cdots k_{l}-1\right)^{k_{1} \cdots k_{l}-1} .
$$

ДокАЗАТЕЛЬСтво. Согласно следствию из леммы 1 имеем неравенство

$$
\tau_{k_{1}}(n) \cdots \tau_{k_{l}}(n) \leqslant \tau_{k_{1} \cdots k_{l}}(n),
$$

поэтому требуемая оценка следует из леммы 2 при $k=k_{1} \cdots k_{l}$.

Полагая в условии теоремы $k_{1}=\cdots=k_{l}=k$, получим следующее следствие, уточняющее оценку (1).

СледСтвиЕ. При любых натуралъных $k \geqslant 2, l$ и любом $X \geqslant 1$ справедлива оценка

$$
\sum_{n \leqslant X}\left(\tau_{k}(n)\right)^{l} \leqslant \frac{X}{\left(k^{l}-1\right) !}\left(\ln X+k^{l}-1\right)^{k^{l}-1} .
$$

\section{СПИСОК ЦИТИРОВАННОЙ ЛИТЕРАТУРЫ}

[1] К. К. Марджанишвили, Докл. АН СССР, 22:7 (1939), 391-393. [2] Д. А. Митькин, Чебышевский сб., 6:1 (2005), 146-156. [3] И. М. Виноградов, Основы теории чисел, Наука, М., 1981. [4] С. М. Воронин, А. А. Карацуба, Дзета-фучкиия Римана, Физматгиз, М., 1994.

\section{Д. А. Митькин}

Поступило

Московский педагогический государственный университет

04.04 .2006 